\title{
A Study of Variation in the Tube Feeding Rate by Nurses in a Tertiary NICU
}

\author{
Krishnegowda $\mathbf{S}^{1}$, Hassan $\mathrm{P}^{2}$, Doreswamy $\mathbf{S M}^{3}$, Veena $\mathbf{S}^{4}$, Hemavathi $\mathbf{M}^{5}$
}

${ }^{1}$ Dr. Sushma Krishnegowda, MD, Fellow Neonatology, Assistant Professor, Department of Paediatrics, JSS Medical college Hospital, MG Road, Mysuru, ${ }^{2} \mathrm{Dr}$. Prajwala Hassan Vasudev, MD, Senior Resident, Department of Paediatrics, ${ }^{3}$ Dr. Srinivasa Murthy Doreswamy, MD, Fellow Neonatal and Perinatal Medicine (Canada), Professor Department of Paediatrics, ${ }^{4}$ Veena S, General nursing and midwifery, Diploma in neonatal nursing, Staff nurse, Department of Neonatology, ${ }^{5} \mathrm{Hemavathi}$ $M$, General nursing and midwifery, Staff nurse, Department of Neonatology. All from the JSS Medical College Hospital, MG Road, Mysuru.

\section{Address for correspondence:}

Dr. Sushma Krishnegowda

Assistant Professor,

Department of Paediatrics, JSS Medical College, Mysuru.

929, 6th main, 10th A cross,

Vijayanagar 1st stage,

Mysuru, India 570017

Tel No; +91-9742299896

E-mail: drsushmasri@gmail.com

Acknowledgements: None

Funding: Nil

Conflict of Interest: None

Permission from IRB: Yes

Ethical dilemmas faced during study: No

\section{How to cite}

Krishnegowda S, Hassan P, Doreswamy SM, Veena S, Hemavathi M. A Study of Variation in the Tube Feeding Rate by Nurses in a Tertiary NICU. J Nepal Paediatr Soc 2016;36(3):222226.

doi: http://dx.doi.org/10.3126/jnps.v36i3.16136

This work is licensed under a Creative Commons Attribution 3.0 License.

\section{(c) (i)}

\begin{abstract}
Introduction: $50-60 \%$ of the low birth weight babies in a neonatal unit are on gravity feed via gavage tube as they often are not strong enough to sustain on oral feeds. Successful feeding depends on nursing skill and individual variation can be expected. As with many other nursing practices in NICU, considerable variation can be expected in gravity feeding rate as well. The objective was to determine the intra individual and inter individual variation in the rate of gravity feeding among the nurses. Material and Methods: This was a Prospective study done in a Tertiary Neonatal care unit. Babies weighing $<2$ kgon enteral feeds were included in study. The nurses carried out feeding in the standard prescribed manner. Time taken for feeds was noted. Results: 21 nurses participated in the study. 15 babies were included and there were 342 feed events. During 75(22\%) feeding events, the nurses had an assignment of less than four babies. During rest of the 267 (78\%) feeding events, they had more than four babies assigned for care. The median volume of feed was $14 \mathrm{ml}$ and median duration was 8 minutes. Feeding rate variation within same nurse varied from one to 37.5 times their base line rate and in between the nurses varied by minimum of 17 times. Conclusion: A wide intra and interpersonal variation among the nurses, with respect to the rate of feeding of newborns was observed in our study.
\end{abstract}

Key words: preterm, gravity feeds, feeding rate

\section{Introduction}

S urvival of the preterm babies is increasing due to the advancements in the neonatal care ${ }^{1}$ Premature or low birth weight babies have a huge challenge before them for survival. Often they have initial stormy course which at times can be fatal. Their immediate survival and subsequent growth and development are strongly influenced by the nutritional advancement ${ }^{2}$ even simple interventions such as early initiation of breastfeeding have been shown to improve their survival in resource restricted settings ${ }^{3}$

Approximately $50-65 \%$ of preterm infants experience feeding intolerance ${ }^{4}$ due to incoordination of suck-swallow reflex. This can 
result in aspiration when fed by oral route. Hence these babies are usually fed by gavage feeds. Even in sick babies, early initiation of tropic feeds through gavage is beneficial ${ }^{5}$. Full feed is typically administered over a period of approximately twenty minutes ${ }^{6}$ bolus as this also mimics a normal feeding time. Gavage feeding involves intense nursing skills and labor in terms of holding the baby semi reclined and lifting the syringe barrel slowly, and hence variation in the feeding rate can be expected. Observation in our unit bolstered our expectation.

According to a recent international survey, feeding practices showed marked variations in neonatal intensive care units in different countries ${ }^{7}$. However most of these studies have considered various methods of gravity feeding. Unfortunately, we could not find any literature looking at the feeding rates with respect to various personal attributes of the health care provider.

We hypothesized that there will be variation in the rate of gravity feeding both within and in between individuals. If so, we wanted to note the magnitude of such variation. The answer to this question would lead to further studies on the effects of rate of gravity feeding on feed tolerance and if needed the strategies to decrease the variation. Hence, we conducted this study to know the extent of variation in gravity feeding rate within individual nursesand in between different nurses at different feeding events. This could help us to device the strategies to bring about uniformity in the feeding rate.

\section{Material and Methods}

This was a hospital based prospective observational study conducted between July 2015 and September 2015 in neonatal unit of JSS Medical college Hospital, JSS University, Mysuru, Karnataka, India. Babies weighing less than $2 \mathrm{~kg}$ who could not be fed orally but tolerating enteral feeds of at least $50 \%$ of their fluid requirement through gavage were included in the study. Sick babies on ventilator and on inotropes were excluded.

All the babies included in the study, had either orogastric or naso gastric tube size $6 \mathrm{Fr}$ inserted and fixed at appropriate length. The position of the tube was initially confirmed by determining of acidic $\mathrm{pH}$ of the aspirated juice using $\mathrm{pH}$ paper. ${ }^{7,8,9}$ Once the position was confirmed, the graduation at which the tube was secured to face was noted and confirmed before each feed to make sure the tube had not migrated. The nurse in charge then administered the feed by filling the prescribed volume of milk into a syringe barrel and connecting it to the gavage tube. She would gradually raise the tube to empty the milk. Following feeding, babies were burped and laid on their beds.

All the nursing staff in charge of babies on gravity feeding filled in the nursing observation sheet with the details of babies assigned to them, onset and conclusion of feeding (burping time not included) one of the investigators collected this data along with other demographic data such as weight, gender and gestation from the case notes.

All these data was entered into Microsoft excel 2013. Continuous variables are summarised as mean and standard deviation or median and interquartile range depending on their distribution. Categorical variables are expressed as proportions

Institutional Ethical committee clearance was obtained. As this was a quality improvement exercise, no special consent was needed

\section{Results}

There were total of 21 nurses who participated and 15 babies were included and there were 342 feed events. 170 feeding events between 6 am to $6 \mathrm{pm}$ were considered as day feeds and 172 feeding events between $6 \mathrm{pm}$ to 6 am were considered as night feeds. During $75(22 \%)$ feeding events, the nurses had an assignment of less than four babies. During rest of the 267 (78\%) feeding events, they had more than four babies assigned for care. The nursing work load in terms of babies assigned was equally distributed between day and night. During $133(39 \%)$ of the day and 134 (39\%) of the night feeding events, the nurses had more than four babies assigned. Only during $37(11 \%)$ of the feeding at day and $38(11 \%)$ at night, the nurses had less than four babies assignment [Table 1].

The median volume of feed was $14 \mathrm{ml}$ and median duration was $8 \mathrm{mins}$. The mean rate was $1.1 \mathrm{ml} / \mathrm{kg} / \mathrm{min}$. The table 2 depicts the feed duration, volume and rate in detail.

Feeding rate variation within same nurse varied from one to 37.5 times their base line rate. Whisker box plot [Figure 1] depicts the spread of variation, median and interquartile range.

Variation of feeding rate in between nurses was also wide. The minimum slowest rate of feeding was $0.1 \mathrm{ml} / \mathrm{min}$ and maximum slowest rate was $2.0 \mathrm{ml} / \mathrm{min}$, amounting to a variation of 30 times. The minimum and 
maximum fastest feeding rate was $0.5 \mathrm{ml} / \mathrm{min}$ and $9.0 \mathrm{ml} /$ min respectively and this amounted to a variation of 17 times. Overall minimum feeding rate was $0.1 \mathrm{ml} / \mathrm{min}$ and maximum feeding rate was $9 \mathrm{ml} / \mathrm{min}$.
There was no correlation between the mean feed volume and the variation in the feeding rate of the nurses [Figure 2]

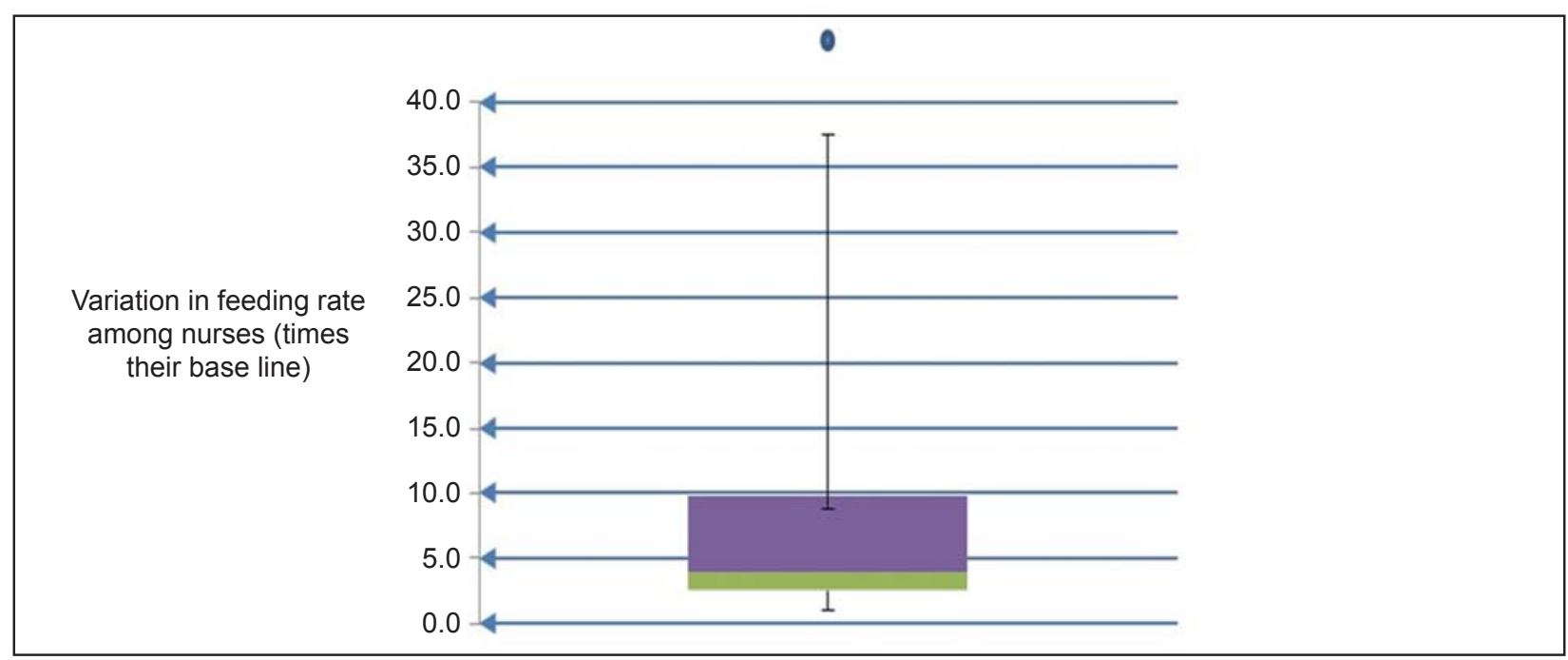

Fig 1: Feeding rate variation among the nurses

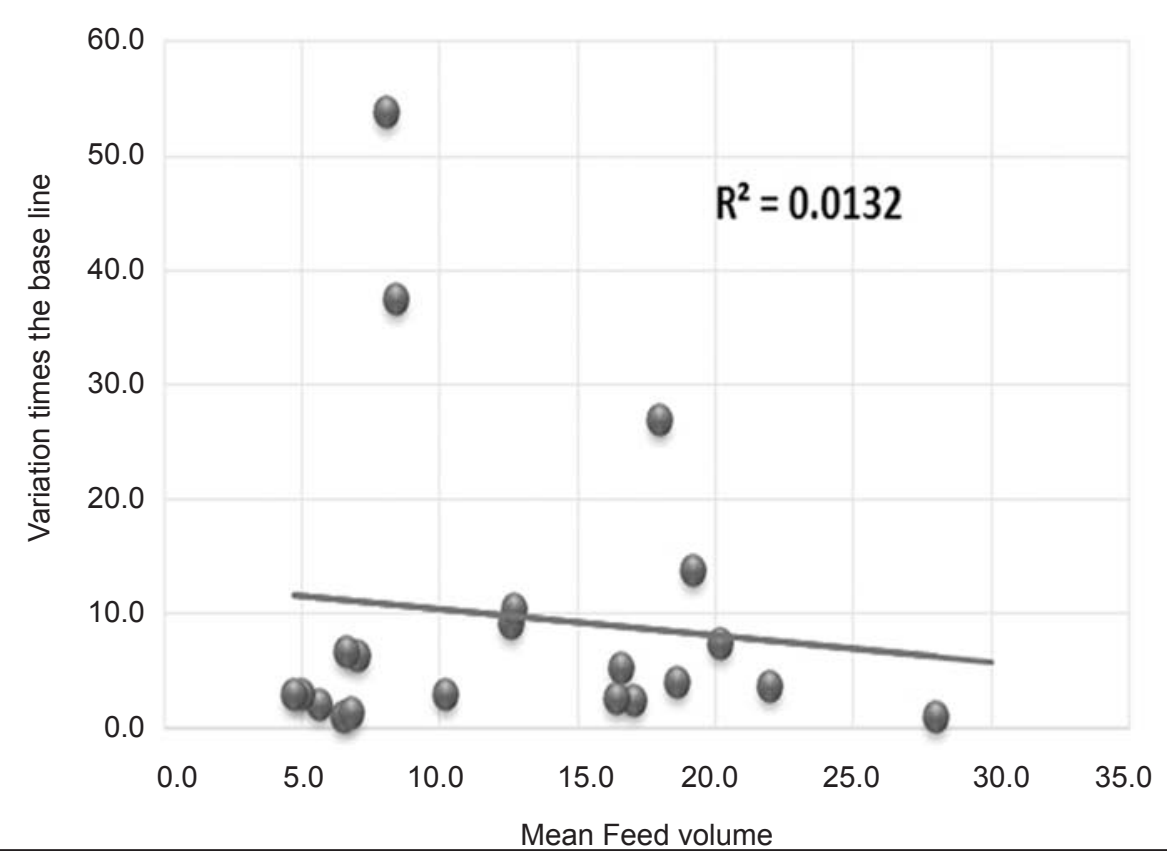

Fig 2: Correlation between mean feed volume and variation in the feeding rate

Table 1: Baby and Feeding event characteristics

\begin{tabular}{lc}
\hline Parameter & Summery statistics \\
\hline Birth weight in grams & $1511(382)[1120-2480]$ \\
Mean (SD)[Range] & \\
Total No of babies $=15$ & $19(8-28)[2-78]$ \\
\hline Feeding event per Nurse & \\
Median (IQR) [ Range] & $170(50 \%)$ \\
Total events = 342 & $172(50 \%)$ \\
\hline Day feeds events $-\mathrm{n}(\%)$ & \\
\hline Night feeds events $-\mathrm{n}(\%)$ & \\
\hline
\end{tabular}


Table 2: Nurse's work attributes and rate of feeding

\begin{tabular}{|c|c|}
\hline \multicolumn{2}{|l|}{ Overall assignment } \\
\hline Parameter & Median (IQR) \\
\hline Duration (min) of feeding & $8(5-12)$ \\
\hline Volume $(\mathrm{ml})$ of milk & $14(6-21)$ \\
\hline Feeding rate $-\mathrm{Vol} / \mathrm{min}$ & $1.7(1.0-2.4)$ \\
\hline Feeding rate corrected for weight $\mathrm{Vol} / \mathrm{Kg} / \mathrm{min}$ & $1.1(0.7-1.7)$ \\
\hline \multicolumn{2}{|l|}{ Baby assignment $>4$ per shift } \\
\hline Duration (min) of feeding & $8(5-12)$ \\
\hline Volume $(\mathrm{ml})$ of milk & $15(5-21)$ \\
\hline Feeding rate $-\mathrm{Vol} / \mathrm{min}$ & $1.8(1-205)$ \\
\hline Feeding rate corrected for weight $\mathrm{Vol} / \mathrm{Kg} / \mathrm{min}$ & $1.2(0.8-1.5)$ \\
\hline \multicolumn{2}{|l|}{ Baby assignment $<4$ per shift } \\
\hline Duration (min) of feeding & $5(3-10)$ \\
\hline Volume $(\mathrm{ml})$ of milk & $10(6-17)$ \\
\hline Feeding rate $-\mathrm{Vol} / \mathrm{min}$ & $1.5(1.1-2.3)$ \\
\hline Feeding rate corrected for weight $\mathrm{Vol} / \mathrm{Kg} / \mathrm{min}$ & $1.2(0.7-1.7)$ \\
\hline \multicolumn{2}{|l|}{ Day shift } \\
\hline Feeding rate - Vol / $\min$ & $1.7(1.2-2.5)$ \\
\hline Feeding rate corrected for weight $\mathrm{Vol} / \mathrm{Kg} / \mathrm{min}$ & $1.1(0.7-1.7)$ \\
\hline \multicolumn{2}{|l|}{ Night shift } \\
\hline Feeding rate - Vol / $\min$ & $1.7(1.0-2.4)$ \\
\hline Feeding rate corrected for weight $\mathrm{Vol} / \mathrm{Kg} / \mathrm{min}$ & $1.2(0.7-1.7)$ \\
\hline
\end{tabular}

\section{Discussion}

Variation in the feeding rate can be expected as the human factor is involved, but the magnitude and the scale of such variation has not been studied in neonatal units. There are various nursing practices where variation between the individuals is substantial and at times matter of concern. well studied practice variation include managing the PICC line ${ }^{10}$, blood sampling volume $^{11}$ rate of blood drawing from umbilical artery ${ }^{12}$ and positioning the babies $^{13}$ Feeding rate variation which could potentially cause feed intolerance is not yet studied.

Our study demonstrated a wide feeding rate variation during gravity feeding. Variation in the slowest feeding rate between the nurses was 30 times and their fastest feeding rate was 17 times the base line.

We did not come across any recommended feeding rate in such stable babies. Literature suggest that the feeds are typically completed in about 20 mins ${ }^{14}$ considering this as a common practice in NICUs and working backwards, a hypothetical baby weighing 1 kilogram on full feeds of 150 to $160 \mathrm{ml} / \mathrm{kg} /$ day, she/he would be getting about 18 to $20 \mathrm{ml}$ feeds every 3 hourly. This volume of milk is recommended to be fed over 15 to
20 mins as it mimics normal feedings and create normal cyclical surges of hormones in the gut. This translates to approximately $1 \mathrm{ml} / \mathrm{kg} / \mathrm{min}$ of feeding rate.

It is interesting to note that when all the data was summarised, the feeding rate noted in our study was appropriate. The matter of concern was the variation among individual nurses and also in-between nurses. This varied from one to 37.5 times the base rate for individual nurse and from 17 to 30 times in-between nurses. This underlines the fact that overall summarized value alone might not actually reflect the gravity of the problem. Our study has demonstrated a wide variation in the feeding rate from a minimum of $0.1 \mathrm{ml} / \mathrm{min}$ to maximum of $9 \mathrm{ml} / \mathrm{min}$ and there was no correlation between the mean feed volume and variation in the feeding rate. This points out towards human factors which can potentially be controlled.

Infants are usually fed every 3 hours over 10-20 mins, it is our common observation that a bolus feeding, when given fast can cause abdomen distension, discomfort in the infant and possibly leading to reflux, an issue of great concern in neonates. On the other hand, the feeds when given slowly, every feed will take 
longer duration and there might not be enough time for digestion before next feeds. There are very few scientific trials to confirm this and a Cochrane review noted that there was a tendency for tachypnea with push feeds compared to gravity feeds ${ }^{15}$

Given the fact that there is gross paucity of evidence regarding the feeding rate, it is safer to assume that current recommendation of slow gravity feeds over 15 to 20 mins as standard of care. We strongly believe that the scale of variation in feeding rate as noted in our study should be addressed on a priority basis. Repeated reinforcing education of the nurses, skill practice sessions may all be helpful to bring about the uniformity in feeding rate. We also believe, the feeding process could be automated, which could achieve this uniformity along with freeing the hands of the nurses who can concentrate on clinical observation. This has a potential to reduce the need for nursing resource as well.

\section{Conclusion}

A wide intra and interpersonal variation among the nurses, with respect to the rate of feeding of newborns is observed in our study. The magnitude of variation with in the nurse baby pair can be as high as 32 times the base line and between the nurses 17 times the base line. This needs further elaborative research to study the impact of such variation on feed intolerance and nourishment of the baby.

\section{References}

1. Avroy A. Fanaroff, MD; Barbara J. Stoll, MD; Linda L. Wright, MD; Waldemar A. Carlo, MD; Richard A. Ehrenkranz, MD; Ann R. Stark, MD; Charles R. Bauer et al. Trends in neonatal morbidity and mortality for very low birthweight infants. Am J Obstet Gynecol 2007:196(2):1-8.

2. Levitsky DA, Strupp BJ. Malnutrition and the brain: changing concepts, changing concerns. J Nutr 1995:125:2212S-20S.

3. Edmond KM, Kirkwood BR, Tawiah CA, Agyei SO Impact of early infant feeding practices on mortality in low birth weight infants from rural Ghana. $J$ Perinatol 2009; 29(2):181.

4. Boo N, Soon C, Lye M. Risk factors associated with feed intolerance in very low birth weight infants following initiation of enteral feeds during the first 72 hours of life. J Trop Pediatr 2000:46(5):272-7.

5. McClure RJ, Newell SJ. Randomised controlled study of clinical outcome following trophic feeding. Arch Dis Child (Fetal and Neonatal Edition). 2000: 82:F29-33.

6. Continuous nasogastric milk feeding versus intermittent bolus milk feeding for premature infants less than 1500 grams. [Cochrane Database Syst Rev. 2011]

7. Premji S1, Chessell L.Klingenberg C, Embleton ND, Jacobs SE,et al. Enteral feeding practices in very preterm infants: an international survey. Arch Dis Child Fetal Neonatal Ed. 2012: 97(1):F56-61

8. Ellett, M. L. C., \& Beckstrand, J. Examination of gavage tube placement in children. $J$ Soc Pediatr Nur1999;4(2):51-60.
9. Metheny, N. A., Clouse, R.E. Clark, J.M., Reed, L., Wehrle, M. A., \& Wiersema, L. Techniques \& procedures: $\mathrm{pH}$ testing of feeding-tube aspirates to determine placement. Nutr Clin Prac1994:9(5):185-90.

10. Metheny, N. A., Eikov, R., Rountree, V., \& Lengettie, E. Indicators of feeding-tube placement in neonates. Nutr Clin Prac 1999:14(6):307-14.

11. Sharpe E1, Kuhn L, Ratz D, Krein SL, Chopra V. Neonatal Peripherally Inserted Central Catheter Practices and Providers: Results From the Neonatal PICC1 Survey.Adv Neonatal Care. 2016 Dec 29. doi: 10.1097/ANC.0000000000000376.

12. Lin JC1, Strauss RG, Kulhavy JC, Johnson KJ, Zimmerman MB, Cress GA, Connolly NW, Widness JA. Phlebotomy overdraw in the neonatal intensive care nursery.Pediatrics 2000;106(2):E19.

13. Myrna Gordon, Lisa Bartruff, Sara Gordon. Maria Lofgren, John A. Widness. How Fast Is Too Fast?:A Practice Change in Umbilical Arterial Catheter Blood Sampling Using the lowa Model for Evidence-Based Practice.Adv Neonatal Care 2008;8(4):198-207.

14. CoriZarem, Tara Crapnell, Lisa Tiltges, Laura Madlinger, Lauren Reynolds, Karen Lukas, Roberta Pineda. Neonatal Nurses' and Therapists' Perceptions of Positioning forPreterm Infants in the Neonatal Intensive Care Unit Neonatal Network.2013;32(2):110-116. doi:10.1891/0730-0832.32.2.110

15. Jennifer A Dawson Ravinder Summan, Nadia Badawi, Jann $P$ Foster. Push versus gravity for intermittent bolus gavage tube feeding of premature and low birth weight infants. Editorial Group: Cochrane Neonatal Group. 2012 DOI: 10.1002/14651858.CD005249. pub2. 